\title{
Erratum
}

www.modernpathology.org

\section{Breast carcinoma malignancy grading by Bloom-Richardson system vs proliferation index: reproducibility of grade and advantages of proliferation index}

John S Meyer, Consuelo Alvarez, Clara Milikowski, Neal Olson, Irma Russo, Jose Russo, Andrew Glass, Barbara A Zehnbauer, Karen Lister and Reza Parwaresch for the Cooperative Breast Cancer Tissue Resource

Modern Pathology (2005) 18, 1649. doi:10.1038/modpathol.3800479

Correction to: Modern Pathology (2005) 18, 1067-1078. doi:10.1038/modpathol.3800388

Following the publication of the above paper, the publisher has identified an error in the horizontal
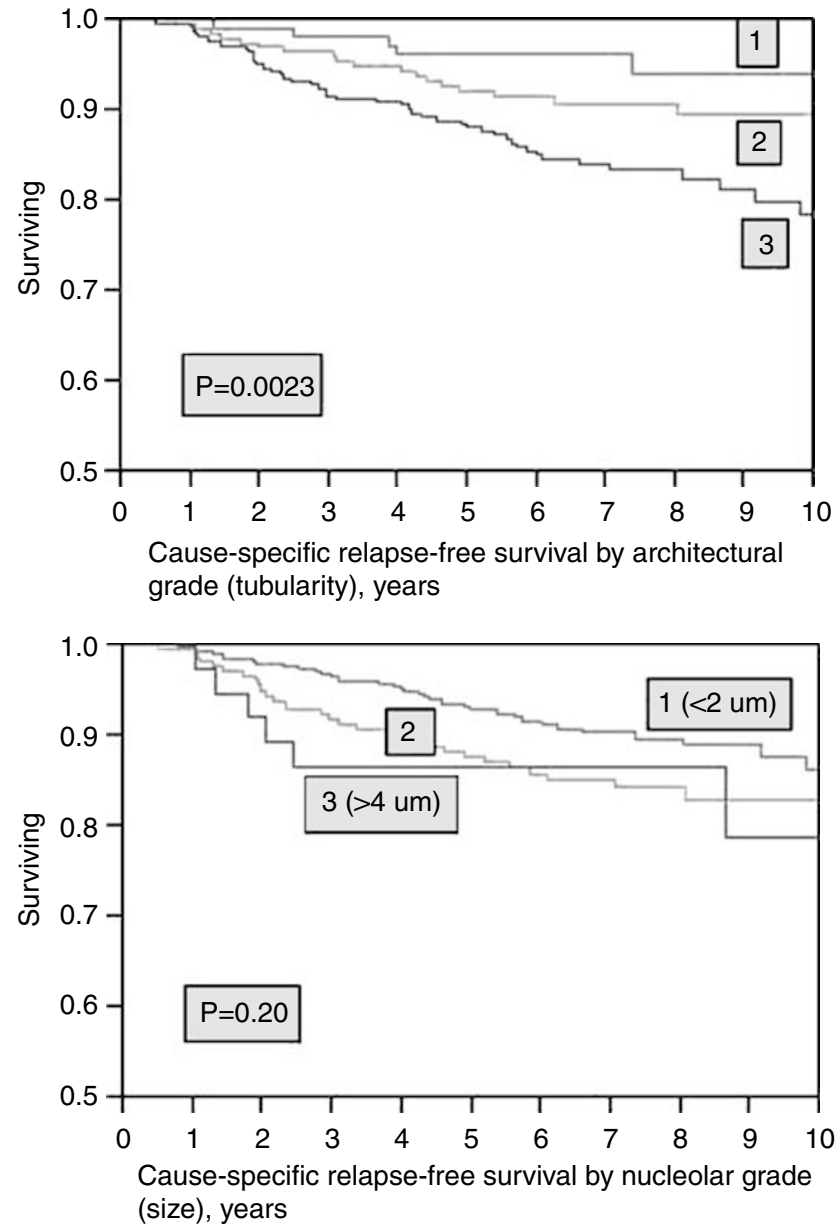

label of the second left panel of Figure 2. The correct Figure 2 is listed below.
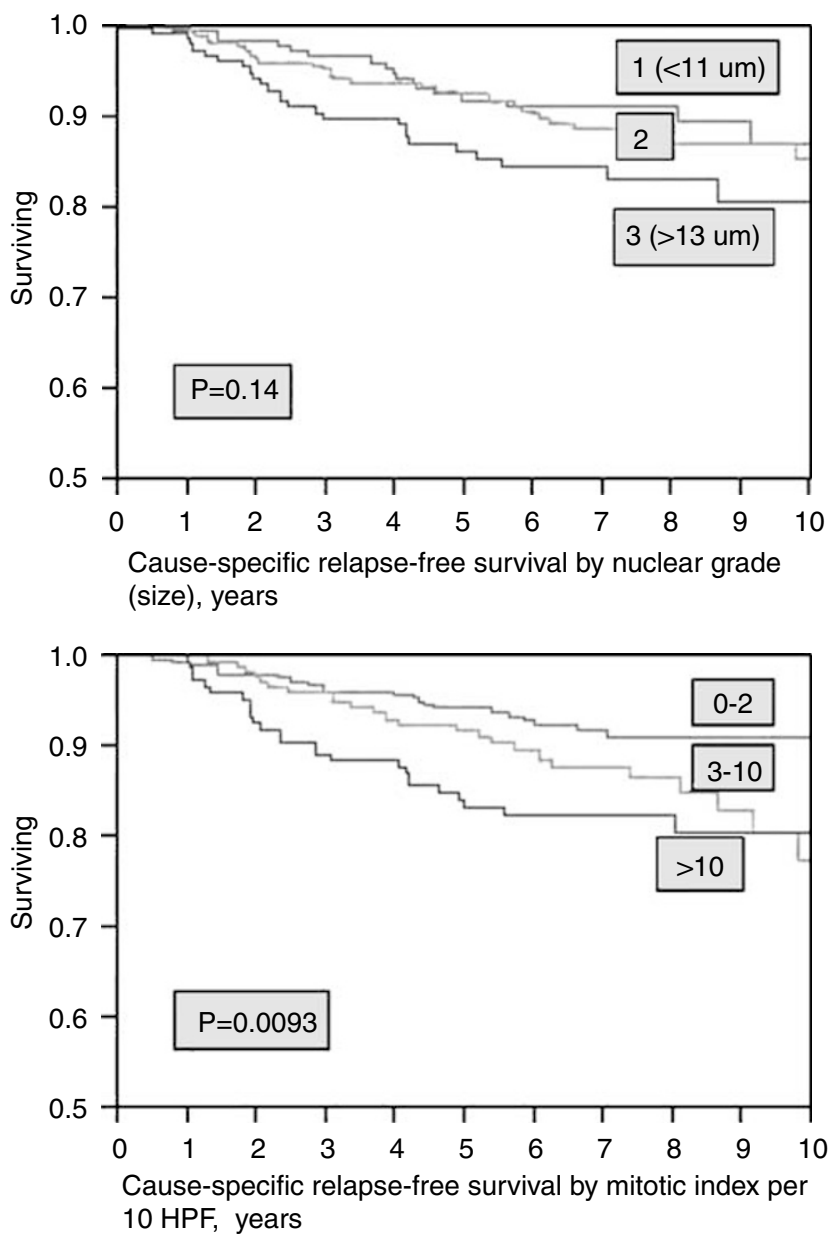

Figure 2 Cause-specific relapse-free survival plot of 631 node-negative breast carcinomas according to tubularity, nuclear size, nucleolar size, and mitotic index. 